\title{
Synthesis of Poly(arylenesiloxane) via Reactions of Oligocyclic Carbonate and Polycarbonate with Cyclosiloxanes
}

\author{
Kazuaki Yokota, ${ }^{\dagger}$ Toyoji KaKuchi, ${ }^{*}$ Nobuto Fukui, Takeo Kuroda, Yasushi Morimoto, \\ Eiji Hamaya, Ichiki Murase, ${ }^{* *}$ and Ryuichi SONODA** \\ Division of Molecular Chemistry, Graduate School of Engineering, Hokkaido University, \\ Sapporo 060, Japan \\ * Division of Bioscience, Graduate School of Environmental Earth Science, Hokkaido University, \\ Sapporo 060, Japan \\ ** Sumitomo Chemical Co., Ltd., Shinkawa, Cyuo-ku, Tokyo 104, Japan
}

(Received July 5, 1996)

\begin{abstract}
Bisphenol A (BPA) oligocyclic carbonate (1) and polycarbonate were reacted with cyclosiloxanes to give copoly(siloxane/carbonate)s. The reaction of cyclocarbonate 1 with hexaphenylcyclotrisiloxane (2) at $210^{\circ} \mathrm{C}$ proceeded with decarboxylation to convert copoly(siloxane/carbonate) to poly(arylenesiloxane). In the reaction of BPA polycarbonate with cyclosiloxane 2, diphenylsiloxane units were favorably inserted into BPA polycarbonate to form copoly(siloxane/carbonate). This reaction was accompanied in part with decarboxylation to convert silylcarbonate into siloxane linkages. The reaction of BPA polycarbonate with decamethylcyclopentasiloxane used benzophenone as a solvent to obtain a homogeneous system. The decarboxylation proceeded with increasing insertion of dimethylsiloxane units. The reaction of BPA polycarbonate and polydimethylsiloxane gave a block-type copolymer.

KEY WORDS Polycarbonate / Oligocyclic Carbonate / Cyclosiloxane / Copolymerization / Insertion Reaction / Copoly(siloxane/carbonate) / Poly(arylenesiloxane)/ Decarboxylation /
\end{abstract}

Bisphenol A (BPA) polycarbonate is commercially produced by transesterification or Schotten-Baumann reaction. The ring-opening polymerization of BPA oligocyclic carbonate (1) is used to prepare BPA polycarbonate by the GE chemists. ${ }^{1-3}$ The new technique through the ring-opening polymerization of oligocyclic intermediates evoked much interest ${ }^{4}$ and has expanded to the methods for preparing block-copoly(siloxane/ carbonate), alt-copoly(amide/carbonate), alt-copoly(ester/carbonate), alt-copoly(ketone/carbonate), alt-copoly(sulfone/carbonate), and alt-copoly(urethane/carbonate). ${ }^{5,6}$ In addition to polycarbonates, new cyclic compounds were adapted to prepare polyarylate, polyaramide, alt-copoly(ether/imide), alt-copoly(ether/sulfone), and alt-copoly(ether/ketone). ${ }^{7,8}$

Many attempts have been made to produce block-copoly(siloxane/carbonate)s for important applications. ${ }^{9}$ It is pointed out that cyclocarbonate $\mathbf{1}$ rather than the phosgene route is useful for carbonate block in the copolymer. ${ }^{6}$ Synthetic approaches are devised to avoid the formation of unstable silylcarbonate linkage in the copolymer. $^{6,9}$

This article describes the ring-opening copolymerization of cyclocarbonate 1 with hexaphenylcyclotrisiloxane (2) to obtain copoly(siloxane/carbonate) having the silylcarbonate linkage. The reaction further proceeded to convert the copolymer to poly(arylenesiloxane) via thermal decarboxylation. Such decarboxylation is found in reactions with cyclosiloxanes, even when commercially available BPA polycarbonate is used as an alternate to cyclocarbonate 1 prepared by a rather complex method. The reaction based on BPA polycarbonate is extended to the polymer/polymer reaction with polydimethylsiloxane.

\footnotetext{
† To whom correspondence should be addressed.
}

\section{EXPERIMENTAL}

Ring-Opening Copolymerization of BPA Oligocyclic Carbonate (1) with Hexaphenylcyclotrisiloxane (2)

To a solution of cyclocarbonate $1(0.5 \mathrm{~g}, 1.97 \mathrm{mmol}$ of repeat unit) and cyclosiloxane $2(0.5 \mathrm{~g}, 2.52 \mathrm{mmol}$ of repeat unit) in dry methylene chloride $(10 \mathrm{~mL})$ was added an appropriate amount of a $0.1 \mathrm{~mol} \mathrm{~L}^{-1}$ solution of potassium phenoxide (PhOK) in tetrahydrofuran (THF). After evaporation of the solvent the solid residue was dried under reduced pressure. The white solid was charged into a glass tube in an atmosphere of nitrogen. The polymerization was run in the tube heated at the polymerization temperature using a steel tube oven. After the product was dissolved in a small amount of methylene chloride, the polymer was isolated by pouring the viscous solution into methanol.

\section{Reaction of BPA Polycarbonate with Hexaphenylcyclo- trisiloxane (2)}

A solution of BPA polycarbonate $(0.5 \mathrm{~g}, 1.97 \mathrm{mmol}$ of repeat unit), cyclosiloxane $2(0.5 \mathrm{~g}, 2.52 \mathrm{mmol}$ of repeat unit), and $\mathrm{PhOK}$ (appropriate amount of $0.1 \mathrm{~mol} \mathrm{~L}^{-1}$ solution in THF) in dry methylene chloride $(10 \mathrm{~mL})$ was evaporated and the residual solid was used for reaction by a procedure similar to that for the polymerization of cyclocarbonate 1 with cyclosiloxane 2. After filtration of a methylene chloride solution of the product, the polymer was isolated by pouring the filtrate into acetone.

\section{Reaction of BPA Polycarbonate with Decamethylcyclo- pentasiloxane (6)}

A methylene chloride solution of polycarbonate $(0.5 \mathrm{~g}$, $1.97 \mathrm{mmol}$ of repeat unit), cyclosiloxane $6(0.5 \mathrm{~g}, 6.74$ mmol of repeat unit), PhOK (appropriate amount of $0.1 \mathrm{~mol} \mathrm{~L}^{-1}$ solution in THF), and benzophenone $(1.0 \mathrm{~g})$ 
was evaporated and the residue was used for the reaction by a procedure similar to that for the polymerization of cyclocarbonate $\mathbf{1}$ with cyclosiloxane 2 . After filtration of a methylene chloride solution of the product, the polymer was isolated by pouring the filtrate into methanol.

\section{Reaction of BPA Polycarbonate with Polydimethylsilox-} ane $(\mathbf{8})$

A methylene chloride solution of polycarbonate $(0.5 \mathrm{~g}$, $1.97 \mathrm{mmol}$ of repeat unit), polydimethylsiloxane $8(0.3 \mathrm{~g}$, $4.05 \mathrm{mmol}$ of repeat unit), and $\mathrm{PhOK}$ (appropriate amount of $0.1 \mathrm{~mol} \mathrm{~L}^{-1}$ solution in THF) was evaporated and the residual solid was used for the reaction by the method described above. The product was purified by reprecipitation (methylene chloride/methanol).

\section{Measurements}

${ }^{1} \mathrm{H}$ NMR spectra were recorded using a JEOL EX270. IR spectra were recorded on a JASCO A-102 spectrophotometer. The molecular weights of the polymers were measured by gel permeation chromatography (GPC) in THF on a Waters M45 high-performance liquid chromatograph equipped with three polystyrene gel columns (Shodex KF-804L). The number-average molecular weight $\left(M_{n}\right)$ was calculated using polystyrene calibration.

\section{RESULTS AND DISCUSSION}

\section{Ring-Opening Copolymerization of BPA Oligocyclic Car- bonate (1) and Hexaphenylcyclotrisiloxane (2)}

The copolymerization of cyclocarbonate 1 with cyclosiloxane 2 was carried out in bulk at $210^{\circ} \mathrm{C}$ using a PhOK catalyst (eq 1). The results are summarized in Table I. Polymers 3 obtained were soluble in methylene chloride, chloroform, and tetrahydrofuran. The yields and molecular weights of polymers 3 decreased with the amount of catalyst. A GPC trace of polymer $\mathbf{3 b}$ exhibited the characteristics of a unimodal distribution with a $M_{w} / M_{n}$ ratio of 1.75 , thus indicating the formation of a copolymer. The molar ratio of BPA units $\left(M_{1}\right)$ to siloxane units $\left(M_{2}\right)$ in the polymers was estimated from ${ }^{1} \mathrm{H}$ NMR signal areas. The $M_{1} / M_{2}$ ratio ranged from $0.45 / 0.55$ to $0.40 / 0.60$ in the copolymer, being $0.44 / 0.56$ in the feed. Copolymerization occurred without considerable change of composition from the feed to the copolymer.

Figure 1 shows the IR spectra of polymers $\mathbf{3 a}$ and

Table I. Ring-opening copolymerization of BPA oligocyclic carbonate (1) with hexaphenylcyclotrisiloxane (2) ${ }^{a}$

\begin{tabular}{|c|c|c|c|c|c|}
\hline & Catalyst & Yield $^{\mathrm{b}}$ & & & Copolymer composition $^{d}$ \\
\hline & $\mu \mathrm{mol}$ & $\%$ & & & $M_{1} / M_{2}$ \\
\hline $\mathbf{3 a}$ & 1.5 & 66 & 6.4 & 1.63 & $0.45 / 0.55$ \\
\hline $3 b$ & 4.5 & 53 & 4.0 & 1.75 & $0.45 / 0.55$ \\
\hline $3 c$ & 15.0 & 20 & 3.5 & 1.46 & $0.40 / 0.60$ \\
\hline
\end{tabular}

${ }^{\text {a }}$ Conditions: cyclocarbonate $1,0.5 \mathrm{~g}$; cyclosiloxane $2,0.5 \mathrm{~g}$; catalyst, PhOK; temp, $210^{\circ} \mathrm{C}$; time, $60 \mathrm{~min}$. ${ }^{\mathrm{b}}$ Acetone-insoluble and $\mathrm{CH}_{2} \mathrm{Cl}_{2^{-}}$ soluble part. ${ }^{\mathrm{c}}$ Determined by GPC. ${ }^{\mathrm{d}}$ Molar ratio of BPA unit $\left(M_{1}\right)$ to siloxane unit $\left(M_{2}\right)$ determined by ${ }^{1} \mathrm{H}$ NMR spectra. 3c by comparison with that of BPA polycarbonate. Intensity at $1750 \mathrm{~cm}^{-1}$ due to the carbonate group was extremely low in polymer 3a and the absorption almost disappeared in polymer 3c. The diminution or disappearance suggests decarboxylation to convert silylcarbonate linkages into siloxane ones in the polymers, as shown in eq 2 .
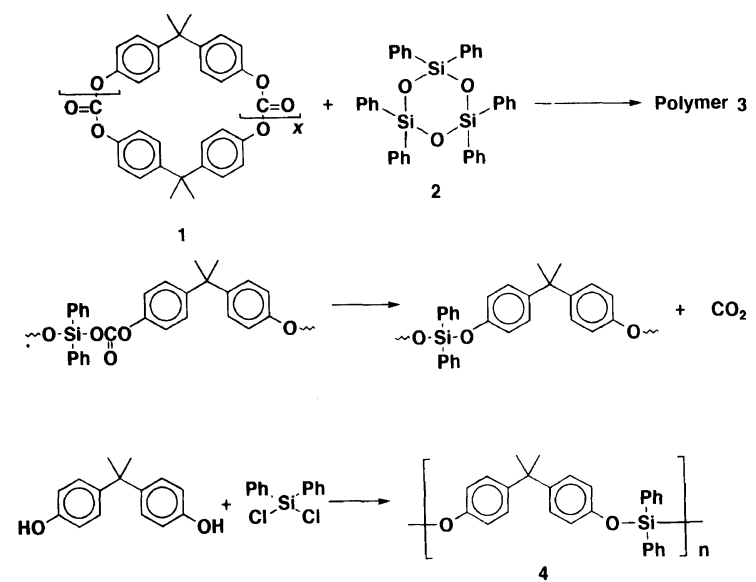

To confirm the decarboxylation, therefore, the model polymer (4) was prepared by the direct condensation of BPA and dichlorodiphenylsilane according to eq 3 . Figure 2 shows the ${ }^{1} \mathrm{H}$ NMR spectra of polymers 3a, 3c, and 4. Polymer $3 c$ gave the IR and ${ }^{1} \mathrm{H}$ NMR spectra identified with those of polymer 4 , due to complete decarboxylation. Three methyl signals are found in the ${ }^{1} \mathrm{H}$ NMR spectrum of polymer 3a, in which a signal at higher field agrees with the methyl proton signal in polymer 4 and another one at lower field with that in BPA polycarbonate. The middle signal, therefore, should be due to the methyl proton signal in the BPA unit having a siloxane and carbonate linkage on each side. The methyl signals at $1.7,1.6$, and $1.5 \mathrm{ppm}$, therefore, are assigned to the structural units $\mathrm{A}, \mathrm{B}$, and $\mathrm{C}$, respectively, in Scheme 1.

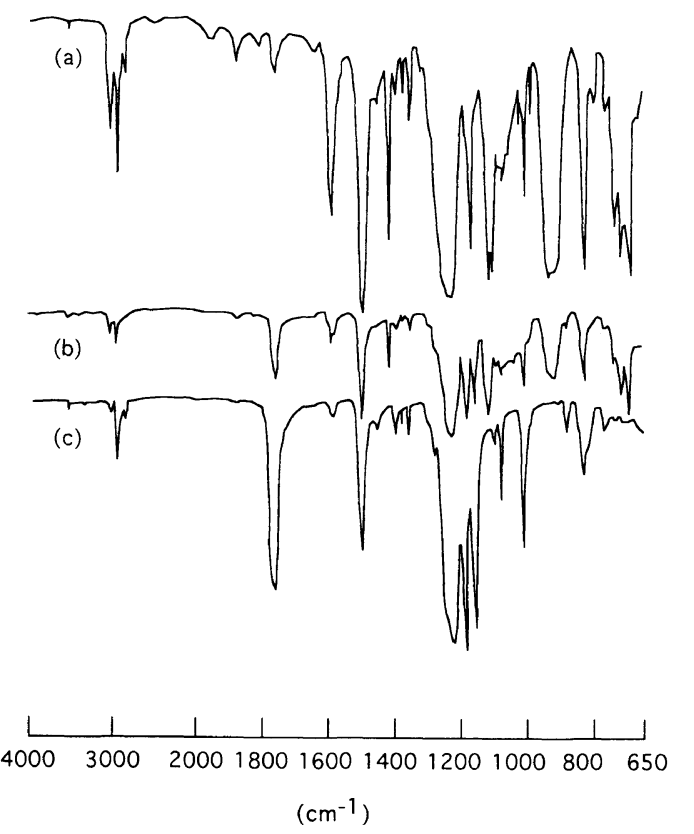

Figure 1. IR spectra of (a) polymer 3c, (b) polymer 3a, and (c) BPA polycarbonate. 


\section{K. YoKota et al.}

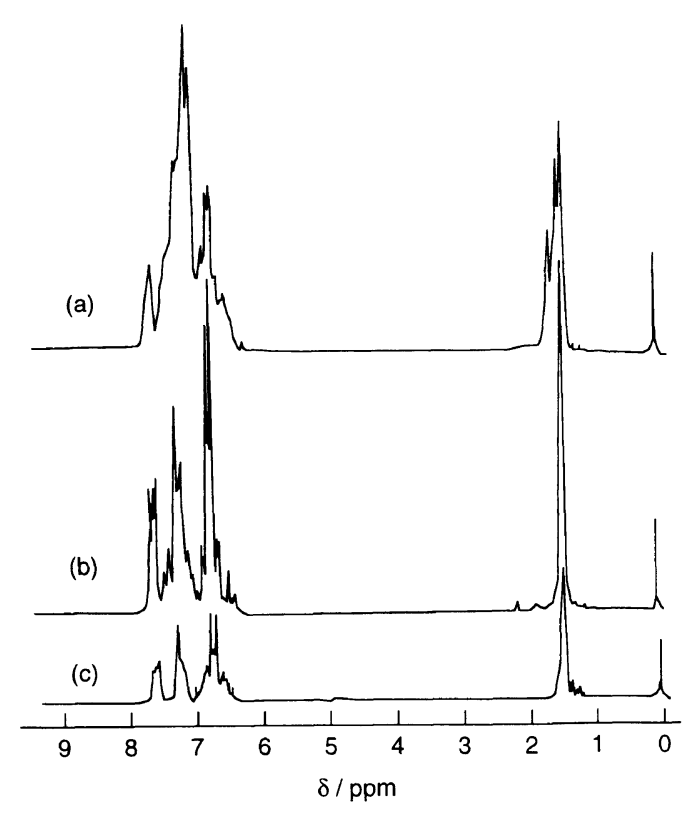

Figure 2. ${ }^{1} \mathrm{H}$ NMR spectra of (a) polymer 3a, (b) polymer 3c, and (c) model polymer 4 .<smiles>COC(=O)Oc1ccc(C(C)(C)c2ccc(OC(=O)OC)cc2)cc1</smiles><smiles>COC(=O)Oc1ccc(C(C)(C)c2ccc(O[Si](OC)(c3ccccc3)c3ccccc3)cc2)cc1</smiles><smiles>CO[Si](Oc1ccc(O[Sb](OC)(c2ccccc2)c2ccccc2)cc1)(c1ccccc1)c1ccccc1</smiles>

Scheme 1.

The random copolymerization of $\mathbf{1}$ and $\mathbf{2}$ was accompanied with cross propagation reactions (eq 4 and 5) to form silylcarbonate linkages. In time, the thermally

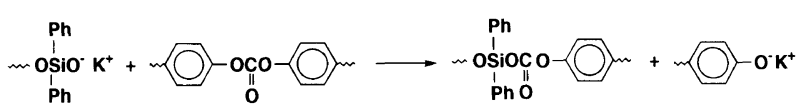

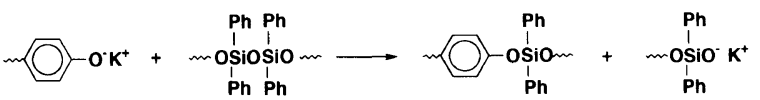

unstable linkage was converted to the siloxane linkage by decarboxylation (eq 2). The general formula of polymer 3 is, thus, written as in Scheme 2 where the following relationship is satisfied: $x>y, z$.

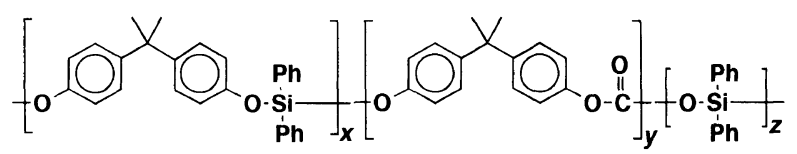

Scheme 2.

Reaction of BPA Polycarbonate with Hexaphenylcyclotrisiloxane (2)

The results of the reaction of BPA polycarbonate with cyclosiloxane $\mathbf{2}$ according to eq 6 are presented in Table

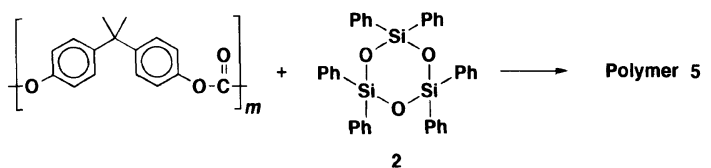

II. The polymers obtained are composed of acetonesoluble and insoluble constituents. When BPA polycarbonate with an $M_{n}$ of 28000 was used in the feed, the acetone-insoluble polymers (5) with $M_{n}$ of 22000 to 36000 were obtained in yields of 12 to $26 \%$. The yields and molecular weights decreased with prolonging reaction time. Molecular weight distributions, estimated as $M_{w} / M_{n}$ of 1.20 to 1.36 , were fairly narrow due to fractionation by which the soluble parts were excluded.

Carbonyl absorption at $1765 \mathrm{~cm}^{-1}$ weakened in intensity in polymers $\mathbf{5 b}$ and $\mathbf{5} \mathbf{f}$ by comparison with that in polycarbonate, thus indicating that this reaction also was accompanied by decarboxylation. The spectrum of polymer 5f was similar to that of polymer 3c except for the slightly remaining absorption due to the carbonyl group.

The ${ }^{1} \mathrm{H}$ NMR spectra of polymers $5 \mathbf{b}, \mathbf{5 g}$, and $\mathbf{5 k}$ in the range $1-2 \mathrm{ppm}$ for methyl protons of the BPA unit are shown in Figure 3. The three methyl signals are assigned to each unit in Scheme 1 as well. The methyl groups in polymers $\mathbf{5} \mathbf{g}$ and $\mathbf{5 k}$ belong to units $\mathrm{A}$ and $\mathrm{C}$, respectively. Polymer $\mathbf{5 b}$ possesses three methyl groups belonging to units $\mathrm{A}, \mathrm{B}$, and $\mathrm{C}$.

The mixed specimens of PBA polycarbonate and polymer 4 corresponding to the carbonate contents of 100 and $0 \%$, respectively, were used for calibrating the amounts of residual carbonyl groups in the polymers. A

Table II. Reaction of BPA polycarbonate with hexaphenylcylcotrisiloxane (2) ${ }^{\mathrm{a}}$

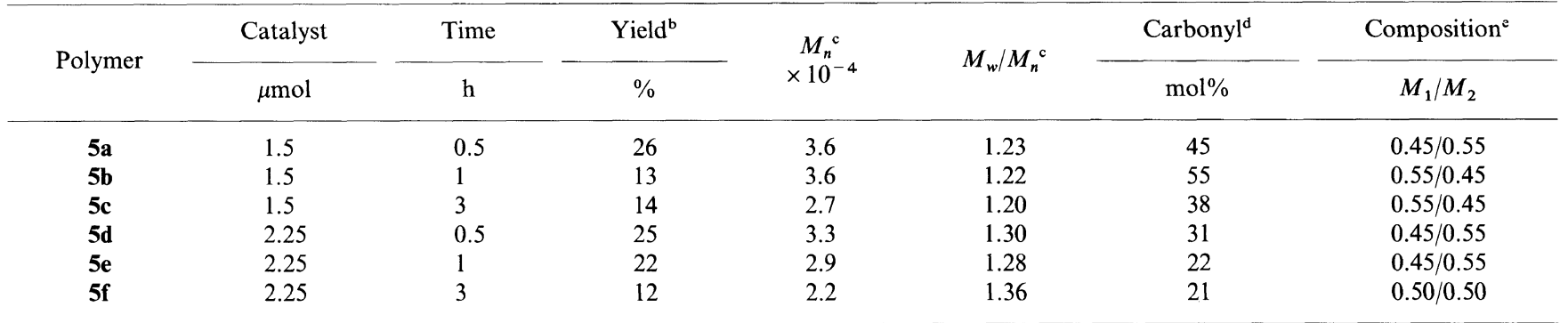

${ }^{\mathrm{a}}$ Conditions: polycarbonate $\left(M_{n}=28000, M_{w} / M_{n}=1.61\right), 0.5 \mathrm{~g}$; cyclosiloxane $2,0.5 \mathrm{~g}$; catalyst, $\mathrm{PhOK}$; temp, $210^{\circ} \mathrm{C}$. ${ }^{\mathrm{b}} \mathrm{Acetone-insoluble} \mathrm{part.}$ ${ }^{\mathrm{c}}$ Determined by GPC. ${ }^{\mathrm{d}}$ Measured by optical density $\left(D_{1770} / D_{1500}\right)$ at 1770 and $1500 \mathrm{~cm}^{-1}$ in the IR spectra. ${ }^{\mathrm{e}} \mathrm{Molar}$ ratio of BPA unit to siloxane unit determined by ${ }^{1} \mathrm{H}$ NMR spectra. 
Table III. Effects of temperature on insertion reaction ${ }^{\mathrm{a}}$

\begin{tabular}{|c|c|c|c|c|c|c|c|}
\hline \multirow{2}{*}{ Polymer } & Temp & Time & Yield $^{\mathrm{b}}$ & \multirow{2}{*}{$\begin{array}{c}M_{n}{ }^{\mathrm{c}} \\
\times 10^{-4}\end{array}$} & \multirow{2}{*}{$M_{w} / M_{n}^{\mathrm{c}}$} & \multirow{2}{*}{$\frac{\text { Carbonyl }^{\mathrm{d}}}{\mathrm{mol} \%}$} & \multirow{2}{*}{$\begin{array}{c}\text { Composition }^{\mathrm{e}} \\
M_{1} / M_{2}\end{array}$} \\
\hline & ${ }^{\circ} \mathrm{C}$ & $\mathrm{h}$ & $\%$ & & & & \\
\hline $5 \mathrm{~g}$ & 180 & 0.5 & 22 & 3.2 & 1.31 & 100 & $0.65 / 0.35$ \\
\hline $5 \mathrm{~h}$ & 180 & 1 & 21 & 2.9 & 1.28 & 85 & $0.60 / 0.40$ \\
\hline $5 \mathbf{a}$ & 210 & 0.5 & 26 & 3.6 & 1.23 & 45 & $0.45 / 0.55$ \\
\hline $5 b$ & 210 & 1 & 13 & 3.6 & 1.22 & 55 & $0.55 / 0.45$ \\
\hline $5 \mathbf{i}$ & 240 & 0.5 & 42 & 3.2 & 1.24 & 28 & $0.50 / 0.50$ \\
\hline $5 j$ & 240 & 1 & 32 & 2.1 & 1.52 & 23 & $0.45 / 0.55$ \\
\hline
\end{tabular}

${ }^{a}$ Conditions: polycarbonate $\left(M_{n}=28000, M_{w} / M_{n}=1.61\right), 0.5 \mathrm{~g}$; cyclosiloxane 2, $0.5 \mathrm{~g}$; catalyst, PhOK $(1.5 \mu$ mol). $\quad$ b,c,d,e See footnotes b, c, $\mathrm{d}$, and e of Table II.

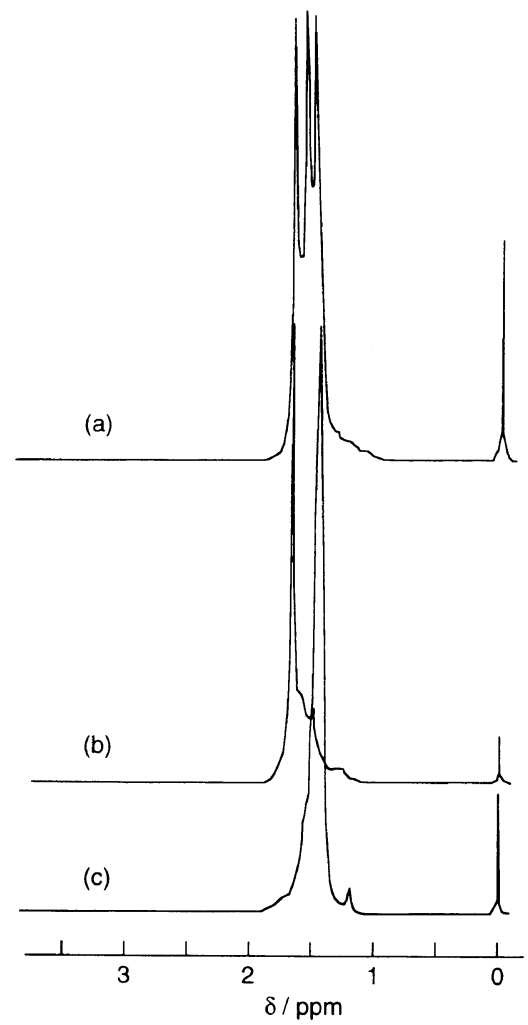

Figure 3. ${ }^{1} \mathrm{H}$ NMR spectra of (a) polymer $\mathbf{5 b}$, (b) polymer $\mathbf{5 g}$, and (c) polymer $\mathbf{5 k}$.

calibration curve was made by plotting the mole per cent of carbonyl content versus the $D_{1770} / D_{1500}$, the ratio of optical density measured at the $1770-\mathrm{cm}^{-1}$ band due to the $\mathrm{C}=\mathrm{O}$ vibration of the carbonate and $1500-\mathrm{cm}^{-1}$ band due to the $\mathrm{C}=\mathrm{C}$ vibration of the aromatic ring. The extent of decarboxylation depended on the amount of catalyst and reaction time, and the former effect was especially remarkable, as shown in Table II. In all cases, yield of insoluble part was low and insertion of the siloxane unit into polycarbonate caused lowering of molecular weight of the polymer. The effects of the reaction temperature are shown in Table III. At $180^{\circ} \mathrm{C}$ the infrequent occurrence of insertion and decarboxylation was observed. At $210^{\circ} \mathrm{C}$ the composition of copolymers was nearly equal to that in the feed, thus indicating that the insertion reaction proceeded very smoothly, but the extent of decarboxylation was $50 \%$. At $240^{\circ} \mathrm{C}$ decarboxylation was $77 \%$ at $1 \mathrm{~h}$.

The $M_{1} / M_{2}$ ratio varied in the range from $0.45 / 0.55$ to $0.55 / 0.45$ in the polymers, being $0.44 / 0.56$ in the feed, (a)

(b)

(c)

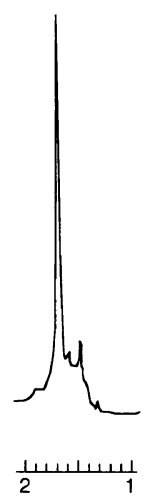

$\delta / \mathrm{ppm}$
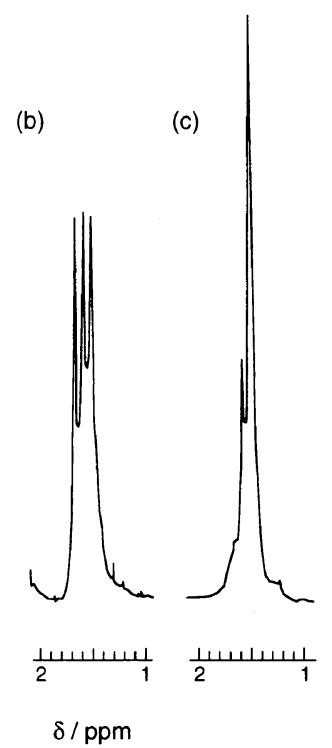

Figure 4. ${ }^{1} \mathrm{H}$ NMR spectra of (a) polymer $\mathbf{5 h}$, (b) polymer $\mathbf{5 b}$, and (c) polymer $\mathbf{5 j}$.

Table IV. Effects of feed molar ratio on insertion reaction ${ }^{\mathrm{a}}$

\begin{tabular}{|c|c|c|c|c|c|c|}
\hline \multirow{2}{*}{ Polymer } & $\begin{array}{l}\text { Feed molar } \\
\text { ratio }^{\mathrm{b}}\end{array}$ & Yield $^{c}$ & \multirow{2}{*}{$\begin{array}{r}M_{n}{ }^{\mathrm{d}} \\
\times 10^{-}\end{array}$} & \multirow{2}{*}{$M_{w} / M_{n}^{\mathrm{d}}$} & \multirow{2}{*}{$\frac{\text { Carbonyl }^{\mathrm{c}}}{\mathrm{mol} \%}$} & \multirow{2}{*}{$\frac{\begin{array}{c}\text { Copolymer } \\
\text { composition }\end{array}}{M_{1} / M_{2}}$} \\
\hline & $M_{1} / M_{2}$ & $\%$ & & & & \\
\hline $5 \mathbf{k}$ & $0.25 / 0.75$ & 20 & 3.1 & 1.33 & 0 & $0.35 / 0.65$ \\
\hline $5 b$ & $0.45 / 0.55$ & 13 & 3.6 & 1.22 & 55 & $0.55 / 0.45$ \\
\hline 51 & $0.63 / 0.35$ & 32 & 3.1 & 1.24 & 55 & $0.60 / 0.40$ \\
\hline
\end{tabular}

${ }^{\mathrm{a}}$ Conditions: catalyst, PhOK $(1.5 \mu \mathrm{mol})$; temp, $210^{\circ} \mathrm{C}$; time, $1 \mathrm{~h}$. ${ }^{b}$ Molar ratio of BPA unit to siloxane unit in the feed. ${ }^{\mathrm{c}, \mathrm{d}, \mathrm{e}, \mathrm{f}}$ See footnotes b, c, d, and e of Table II.

as indicated in Table II. Siloxane units were favorably inserted into BPA polycarbonate to form copoly(siloxane/carbonate). Variation of the composition in polymers $5 \mathbf{h}, \mathbf{b}$, and $\mathbf{j}$, obtained by the reaction for $1 \mathrm{~h}$ at three different temperatures, is shown in Figure 4. Three signals from 1.7 to $1.5 \mathrm{ppm}$ correspond to the structural units $\mathrm{A}, \mathrm{B}$, and $\mathrm{C}$ in Scheme 1 . The reaction at $180^{\circ} \mathrm{C}$ showed cyclotrisiloxane 2 was inserted in the polycarbonate holding a unit of trimer, irrespective of producing the polymer with $M_{1} / M_{2}$ of $0.60 / 0.40$, because the signals at 1.5 and $1.6 \mathrm{ppm}$ are weak in comparison with $1.7 \mathrm{ppm}$. In the reaction at $210^{\circ} \mathrm{C}$, three signals were equal in intensity, indicating the polymer to be composed of three structural units in equal amounts. 
K. Yокота et al.

Table V. Reaction of BPA polycarbonate with decamethylcyclopentasiloxane $(6)^{\mathrm{a}}$

\begin{tabular}{|c|c|c|c|c|c|c|c|}
\hline \multirow{2}{*}{ Polymer } & Catalyst $^{\mathrm{b}}$ & Temp & Yield $^{\mathrm{c}}$ & \multirow{2}{*}{$M_{n}^{\mathrm{d}}$} & \multirow{2}{*}{$M_{w} / M_{n}{ }^{\mathrm{d}}$} & \multirow{2}{*}{$\frac{\text { Carbonyl }^{\mathrm{e}}}{\mathrm{mol} \%}$} & \multirow{2}{*}{$\begin{array}{c}\text { Composition } \\
M_{1} / M_{2}\end{array}$} \\
\hline & $\mu \mathrm{mol}$ & ${ }^{\circ} \mathrm{C}$ & $\%$ & & & & \\
\hline $7 \mathbf{a}$ & 5.0 & 180 & 0 & - & - & - & - \\
\hline $7 b$ & 8.5 & 180 & 59 & 6200 & 1.52 & 97 & $0.81 / 0.19$ \\
\hline $7 c$ & 10.0 & 180 & 25 & 5400 & 1.46 & 73 & $0.70 / 0.30$ \\
\hline $7 d$ & 15.0 & 180 & 22 & 4000 & 1.54 & 44 & $0.56 / 0.44$ \\
\hline $7 e$ & 20.0 & 180 & 14 & 3500 & 1.57 & 37 & $0.61 / 0.39$ \\
\hline $7 f$ & 10.0 & 150 & 14 & 5400 & 1.39 & 92 & $0.82 / 0.18$ \\
\hline $7 g$ & 10.0 & 160 & 32 & 3400 & 1.73 & 76 & $0.65 / 0.35$ \\
\hline $7 \mathrm{~h}$ & 10.0 & 170 & 27 & 3400 & 1.74 & 77 & $0.57 / 0.43$ \\
\hline
\end{tabular}

${ }^{\mathrm{a}}$ Conditions: polycarbonate $\left(M_{n}=28000, M_{w} / M_{n}=1.61\right), 0.5 \mathrm{~g}$; cyclosiloxane 6, $0.5 \mathrm{~g}$; benzophenone, $1.0 \mathrm{~g} ;$ time, $1.0 \mathrm{~h}$. ${ }^{\mathrm{b}} \mathrm{PhOK} . \quad{ }^{\mathrm{c}} \mathrm{MeOH}-$ insoluble and $\mathrm{CH}_{2} \mathrm{CH}_{2}$-soluble part. ${ }^{\text {d,e,f }}$ See footnotes c, d, and e of Table II.

This approximately corresponds to a residual carbonyl content of $55 \%$. By estimating from the $M_{1} / M_{2}$ ratio of $0.55 / 0.45$ in the polymer, about $33 \%$ of the siloxane units still hold the original sequence of trimer in the polymer chain. The structure of the polymer is shown in Scheme 2. In the reaction at $240^{\circ} \mathrm{C}$, the intensity ratio of three signals corresponds closely to a residual carbonyl content of $23 \%$, thus showing steady progress of the reaction.

Variation of the polymer composition and the residual carbonyl content by the feed mole ratios is shown in Table IV. At every ratio in the feed, the polymer composition approached the alternating composition rather than azeotropic one. At a feed $M_{1} / M_{2}$ ratio of $0.25 / 0.75$, decarboxylation smoothly progressed to give the polymer with $y=0$ in Scheme 2 . At $M_{1} / M_{2}$ ratio of $0.45 / 0.55$ and $0.65 / 0.35$, the area ratios of three signals were $1 / 1 / 1$ and $1 / 2.6 / 1$, respectively, which correspond closely to a residual carbonyl content of $55 \%$. The reaction time for $1 \mathrm{~h}$ was insufficient for decarboxylation to go to completion.

Reaction of BPA Polycarbonate with Decamethylcyclopentamer (6)

When a mixture of BPA polycarbonate with cyclodimethylsiloxane, that is, trimer, tetramer, or pentamer, was heated with $\mathrm{PhOK}$ at appropriate temperature, no reaction occurred. Benzophenone, therefore, was used as solvent to establish the homogeneous system.

A mixture of $0.5 \mathrm{~g}$ of polycarbonate and $0.5 \mathrm{~g}$ of cyclosiloxane 6 corresponding to the $M_{1} / M_{2}$ ratio of $0.23 / 0.77$ was heated in benzophenone with $\mathrm{PhOK}$ for $1 \mathrm{~h}$ (eq 7). The results are shown in Table V. In the

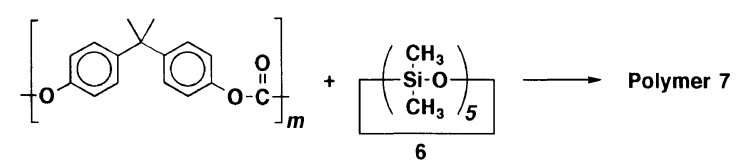

reaction at $180^{\circ} \mathrm{C}$, the insertion of cyclosiloxane 6 into polycarbonate occurred using the catalyst at $8.5 \mu \mathrm{mol}$ or more. The yield and molecular weight of polymer 7 decreased with increasing amount of catalyst, and this was accompanied by increase of dimethylsiloxane units in the polymer composition. There was a marked tendency toward lower molecular weight in every case. Table VI shows the effects of composition in the feed. Excess cyclosiloxane was required for insertion and thus the
Table VI. Effects of feed molar ratio on insertion reaction ${ }^{\mathrm{a}}$

\begin{tabular}{|c|c|c|c|c|c|c|}
\hline \multirow{2}{*}{ Polymer } & $\begin{array}{c}\text { Feed molar } \\
\text { ratio }^{b}\end{array}$ & Yield $^{c}$ & \multirow{2}{*}{$M_{n}^{\mathrm{d}}$} & \multirow{2}{*}{$M_{w} / M_{n}^{\mathrm{d}}$} & \multirow{2}{*}{$\frac{\text { Carbonyl }^{\mathrm{c}}}{\mathrm{mol} \%}$} & \multirow{2}{*}{$\frac{\begin{array}{c}\text { Copolymer } \\
\text { composition }^{\mathrm{f}}\end{array}}{M_{1} / M_{2}}$} \\
\hline & $M_{1} / M_{2}$ & $\%$ & & & & \\
\hline $7 i$ & $0.16 / 0.84$ & 56 & 4500 & 1.65 & 58 & $0.66 / 0.34$ \\
\hline $7 \mathbf{j}$ & $0.30 / 0.70$ & 66 & 3800 & 1.68 & 66 & $0.69 / 0.31$ \\
\hline $7 \mathbf{k}$ & $0.40 / 0.60$ & 43 & 3600 & 1.59 & 73 & $0.72 / 0.28$ \\
\hline 71 & $0.54 / 0.46$ & 30 & 3400 & 1.49 & 83 & $0.81 / 0.19$ \\
\hline
\end{tabular}

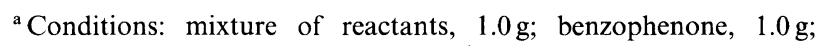
catalyst, PhOK $(10 \mu \mathrm{mol})$; time, $1.0 \mathrm{~h}$. ${ }^{\mathrm{b}}$ See footnote b of Table IV. c,d,e,f See footnotes b, c, d, and e of Table II.

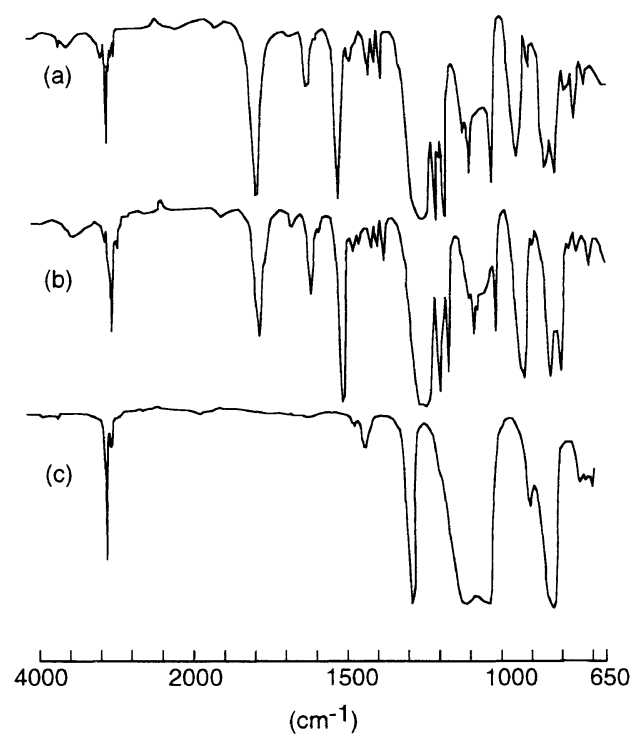

Figure 5. IR spectra of (a) polymer 7c, (b) polymer 7d, and (c) polydimethylsiloxane.

equimolar reaction of two components gave the polymer with the $M_{1} / M_{2}$ molar ratio of $0.8 / 0.2$. The dimethylsiloxane unit was difficult to insert into polycarbonate in comparison with the diphenylsiloxane unit.

The IR spectra of polymers $\mathbf{7 c}$ and $\mathbf{7 d}$ are shown along with that of polydimethylsiloxane in Figure 5. A new absorption at $920-940 \mathrm{~cm}^{-1}$ due to $-\mathrm{Si}-\mathrm{O}-\mathrm{Ar}-$ bond $^{10}$ was found in the polymers obtained. Insertion of the dimethylsiloxane unit into polycarbonate and then the decarboxylation were recognized. Carbonate content was estimated from the calibration curve for polymer 5 . Decarboxylation proceeded with increasing insertion of 


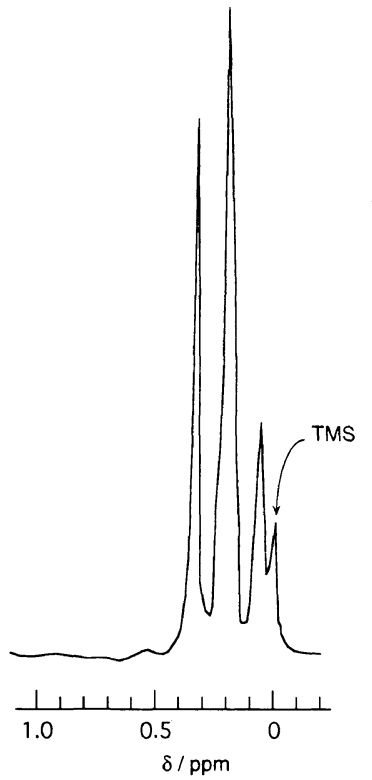

Figure 6. ${ }^{1} \mathrm{H}$ NMR spectrum of polymer $7 \mathrm{~d}$.

dimethylsiloxane units.

The ${ }^{1} \mathbf{H}$ NMR spectrum of polymer $7 \mathbf{d}$ in the range $0-0.5 \mathrm{ppm}$ for the methyl protons in the dimethylsiloxane units is shown in Figure 6. Three signals at 0.05, 0.2, and $0.35 \mathrm{ppm}$ provide significant clarification of the polymer structure. The signal at $0.05 \mathrm{ppm}$ coincides with the methyl proton signal of polydimethylsiloxane, assigned to the methyl proton of unit D in Scheme 3. The two signals at 0.2 and $0.35 \mathrm{ppm}$ are presumed to be units $E$ and $G$, respectively. Splitting of the signals at $0.2 \mathrm{ppm}$ in some of the polymer samples suggests the presence of unit $\mathrm{F}$ in addition to unit $\mathrm{E}$. The structure of polymer 7 is shown in Scheme 4.

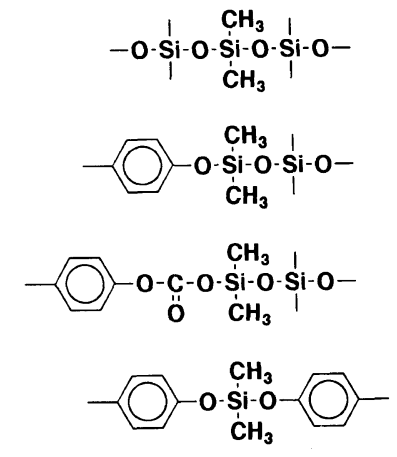

Scheme 3.

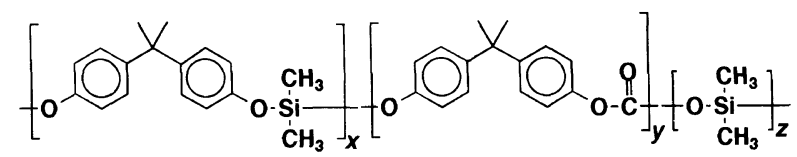

Scheme 4.

\section{Reaction of BPA Polycarbonate and Polydimethylsiloxane}

(8)

A mixture of $0.5 \mathrm{~g}$ of BPA polycarbonate $\left(M_{n}=\right.$ $\left.2.8 \times 10^{4}\right)$ and $0.5 \mathrm{~g}$ of polymer $8\left(M_{w}=1.3 \times 10^{5}\right)$ at a feed molar ratio of $1: 2$ was reacted with PhOK catalyst according to eq 8 . The results are shown in Table VII.
Table VII. Reaction of BPA polycarbonate and polydimethylsiloxane $(\mathbf{8})^{\mathbf{a}}$

\begin{tabular}{|c|c|c|c|c|c|c|}
\hline \multirow{2}{*}{ Polymer } & Catalyst & Temp. & Time & Yield & \multirow{2}{*}{$\begin{array}{c}M_{n}^{\mathrm{b}} \\
\times 10^{-4}\end{array}$} & \multirow{2}{*}{$M_{w} / M_{n}^{\mathrm{b}}$} \\
\hline & $\mu \mathrm{mol}$ & ${ }^{\circ} \mathrm{C}$ & $\mathrm{h}$ & $\%$ & & \\
\hline $9 a$ & 3.0 & 250 & 3 & gel & - & - \\
\hline $9 b$ & 1.5 & 300 & 3 & 45 & 2.0 & 1.57 \\
\hline
\end{tabular}

a Conditions: polycarbonate $\left(M_{n}=28000\right)$; polysiloxane $\left(M_{w}=\right.$ $130000)$; $\mathrm{PC} / \mathrm{SiO}$ molar ratio in feed, $1 / 2$; catalyst, PhOK. ${ }^{\mathrm{b}} \mathrm{De}-$ termined by GPC.

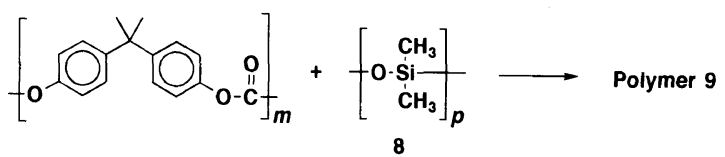

When an appropriate amount of catalyst was used, the $\mathrm{CH}_{2} \mathrm{Cl}_{2}$-soluble polymer (9b) was obtained by fractional precipitation. Polymer 9b showed a unimodal distribution in GPC analysis. The IR and ${ }^{1} \mathrm{H}$ NMR spectra indicated that polymer $\mathbf{9 b}$ was composed of the additive structures of BPA polycarbonate and polymer 8 . The absorption of $-\mathrm{Si}-\mathrm{O}-\mathrm{Ar}-$ bond was not found in the range of $900-1000 \mathrm{~cm}^{-1}$ in the IR spectrum. Polymer $9 \mathrm{~b}$ had the same composition as at the feed ratio of $1: 2$. Because random copolymerization accompanying decarboxylation did not occur, polymer 9b was the blocktype copolymer shown in Scheme 5.

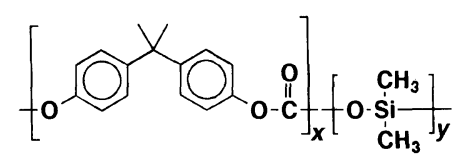

Scheme 5.

\section{Thermal Analysis in Polymer Characterization}

Polymer 3b, prepared from cyclocarbonate 1 and cyclosiloxane 2, showed the weight-loss of $38.4 \%$ at $550^{\circ} \mathrm{C}$ by comparison with those of 73.7 and $97.5 \%$ for BPA polycarbonate and polydiphenylsiloxane, respectively. The thermal stability of polymer $\mathbf{3 b}$ was better than those of the homopolymers. The glass transition temperature $\left(T_{\mathrm{g}}\right)$, measured by DSC analysis, was $88^{\circ} \mathrm{C}$ for polymer $\mathbf{3 b}$ in contrast to $150^{\circ} \mathrm{C}$ for BPA polycarbonate and thus the copolymerization decreased $T_{\mathrm{g}}$.

Polymers $\mathbf{5 b}$ and $\mathbf{5 k}$ had $T_{\mathrm{g}}$ of 92 and $74^{\circ} \mathrm{C}$, respec-

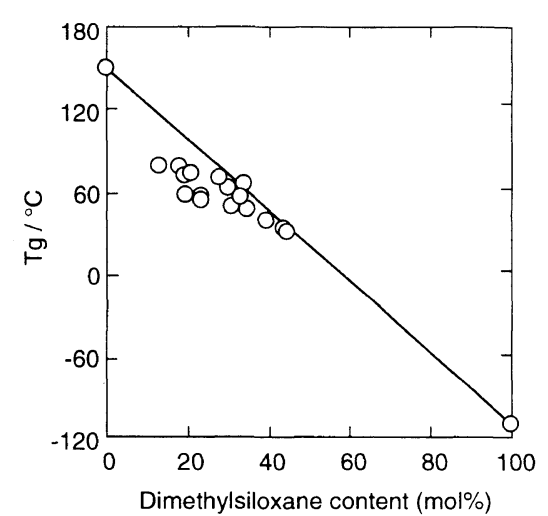

Figure 7. Relationship between $T_{\mathrm{g}}$ and siloxane content for polymers 7. 
tively, in which $M_{1} / M_{2}$ ratios were $0.45 / 0.55$ and $0.36 /$ 0.65 and carbonyl content 22 and zero \%. An increase of the diphenyl siloxane unit led to lower $T_{\mathrm{g}}$. Polymer $5 \mathrm{~g}$ with the $M_{1} / M_{2}$ ratio of $0.65 / 0.35$ and carbonyl content of $100 \%$ showed the transition temperature at $225^{\circ} \mathrm{C}$ corresponding to the $T_{\mathrm{m}}$ of polycarbonate. This indicates the presence of long sequences corresponding to the polycarbonate in the chain, which agrees with the ${ }^{1} \mathrm{H}$ NMR analytical data. Polymer $5 \mathbf{k}$ without carbonate linkages showed the transition temperature at $112^{\circ} \mathrm{C}$ in addition to $T_{\mathrm{g}}$.

The relationship between $T_{\mathrm{g}}$ and siloxane content for polymers 7 is shown in Figure $7 . T_{\mathrm{g}}$ lowered with increasing content of the siloxane along a line joining both homopolymers.

\section{REFERENCES}

1. a) T. L. Evans and D. A. Williams, (GE) U. S. Patent, 4,605,731 (1986). b) T. L. Evans and D. A. Williams, (GE) U. S. Patent, 4,650,852 (1987). c) T. L. Evans and C. B. Berman, (GE) U. S. Patent, 4,701,519 (1987). d) T. L. Evans and C. B. Berman, (GE) U. S. Patent, 4,746,726 (1988).

2. D. J. Brunelle and T. G. Shannon, Macromolecules, 24, 3035 (1991).
3. D. J. Brunelle, E. P. Boden, and T. G. Shannon, J. Am. Chem. Soc., 112, 2399 (1990).

4. a) S. Stinson, C \& EN, Sept. 18, 8 (1989). b) S. Stinson, C \& EN, Sept. 25, 35 (1989).

5. D. J. Brunelle and T. G. Shannon, Makromol. Chem., Macromol. Symp., 42/43, 155 (1991).

6. T. L. Evans and J. C. Carpentner, Makromol. Chem., Macromol. Symp., 42/43, 177 (1991)

7. a) T. L. Guggenheim, S. J. McCormick, J. J. Kelly, D. J. Brunelle, A. M. Colley, E. P. Boden, and T. G. Shannon, Polym. Prepr., Am. Chem. Soc., Div. Polym. Chem., 30(2), 579 (1989). b) J. A. Cella, J. J. Talley, and J. M. Fukuyama, Polym. Prepr., Am. Chem. Soc., Div. Polym. Chem., 30(2), 581 (1989). c) M. J. Mullins, E. P. Woo, C. C. Chen, D. J. Murray, M. T. Bishop, and K. E. Balon, Polym. Prepr., Am. Chem. Soc., Div. Polym. Chem., 32(2), 174 (1991). d) M. J. Mullins, R. Galvan, M. T. Bishop, E. P. Woo, D. B. Gorman, and T. A. Chamberlin, Polym. Prepr., Am. Chem. Soc., Div. Polym. Chem., 33(1), 414 (1992).

8. H. M. Colquhoun, C. C. Dudman, M. Thomas, C. A. O'Mahoney, and D. J. Williams, J. Chem. Soc., Chem. Commun., 336 (1990).

9. a) H. A. Vaughn, J. Polym. Sci., B, 7, 569 (1969). b) J. S. Rffle, R. G. Freelin, A. K. Banthia, and J. E. McGrath, J. Macromol. Sci., Pure Appl. Chem., A15, 967 (1981). c) H. Rosenberg and T.-T. Tsai, J. Polym. Sci., Polym. Chem. Ed., 20, 1 (1982). d) P. J. McDermott, T. E. Krafft, and J. D. Rich, J. Polym. Sci., A, Polym. Chem., 29, 1681 (1991).

10. R. M. Silverstein, G. C. Bassler, and T. C. Morrill, "Spectrometric Identification of Organic Compounds," John Wiley \& Sons, New York, N. Y., 1981, p 175. 